\title{
Drugs of abuse in drinking water - a review of current detection methods, occurrence, elimination and health risks
}

\author{
Yan Peng, Sarah Hall *, Lata Gautam \\ Forensic and Investigative Sciences Research Group, Department of Biomedical and Forensic Sciences, Faculty of Science and Technology, \\ Anglia Ruskin University, Cambridge CB1 1PT, UK
}

\section{A R T I C L E I N F O}

\section{Keywords:}

Drugs of abuse

Novel psychoactive substances

Drinking water

Solid phase extraction

Chromatography-mass spectrometry

Trace analysis

Potential risk to human health

\begin{abstract}
A B S T R A C T
This review focuses on the drugs of abuse in drinking water, as their presence is of increasing global concern and trace levels of these compounds have previously been detected. Even though these levels are not toxic with long term exposure via drinking water, they have the potential to bio accumulate and be in toxic to humans. In addition, transformation of these compounds during water treatment processes and their effect need further investigation as there are recent reports highlighting the increased toxicity to freshwater species. Currently there is limited information available on the detection of emerging drugs, therefore high resolution mass analyser could be a suitable alternative for non-target screening. Depending on the water treatment method used, the level of drugs of abuse detected can vary. Therefore, water regulatory bodies need to enforce more effective treatment methods for safe and sustainable drinking water.
\end{abstract}

(c) 2016 Elsevier B.V. All rights reserved.

\section{Contents}

1. Introduction

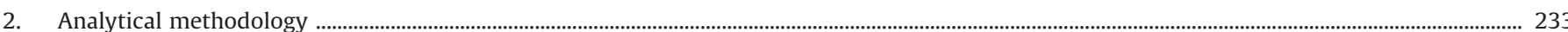

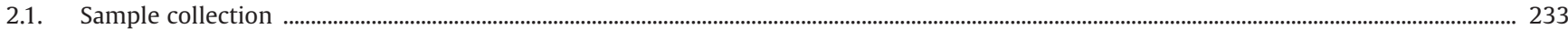

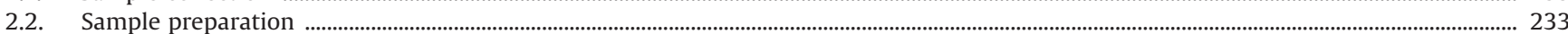

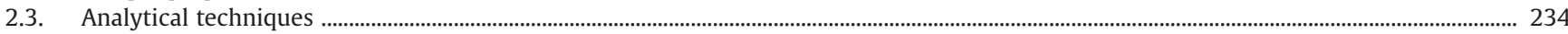

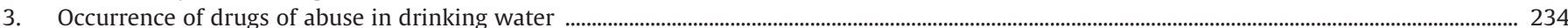

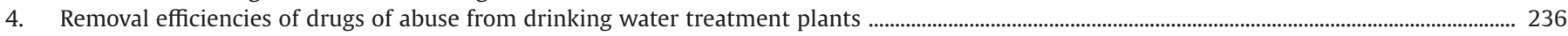

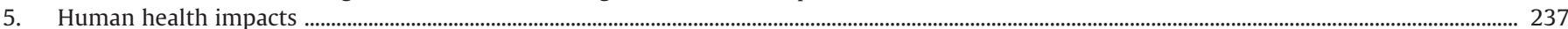

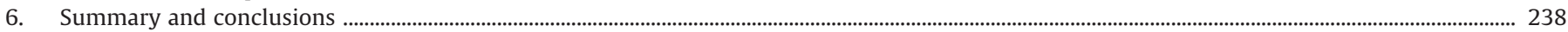

Uncited references ...

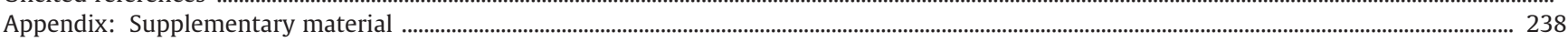

References .... 238

\section{Introduction}

Since endocrine disrupting compounds, such as pesticides, have been detected in the aquatic environment, the presence of water pollutants has led to growing public attention and scientific interest, particularly with their adverse effects on human health [1,2]. In the last few years, research has turned to the study of new emerging water contaminants, such as drugs of abuse [3], which may have an associated negative impact on the environment and health.

\footnotetext{
* Corresponding author. Tel.: +01223 363271 ext. 2170; fax: 08451165056

E-mail address: sarah.hall@anglia.ac.uk (S. Hall).
}

Drugs of abuse have been reported to be present in not only drinking water but also other aquatic systems including waste, surface and ground waters $[3,4]$. The major entry route of these contaminants into waste water is via human waste as both parent compound and their metabolites [5]. The waste water is processed at a treatment plant but some drugs of abuse still remain as contaminants in the effluent, as they are not completely removed [3]. Subsequently the treated effluents are then released into surface water, such as rivers and lakes [5]. Once present in the surface water, these compounds can further contaminate ground water via natural seepage and leaking sewer systems [4].

Recent studies have reported the presence of drugs of abuse in drinking water at trace levels $(\mathrm{ng} / \mathrm{L})$ and this raises concerns 
regarding their route of entry $[5,6]$. When using raw water (abstracted from surface or ground water) for drinking water, they still contain such compounds after treatment $[5,6]$. This is owing to drinking water treatment plants (DWTPs) only removing contaminants included in and to the levels set out in the regulatory requirements $[7,8]$.

To date, most reviews focus on waste water [5,9-12], surface water $[5,9,13]$ and ground water $[4,5,14]$ regarding the presence of drugs of abuse. However, with drinking water, there are only a few reviews [5]. The paper by Pal, et al [5] reviews the available literature regarding the presence of drugs of abuse in drinking water including information on the presence of newer emerging drugs.

This review gives a comparative overview of the sample preparation and analytical methodologies (Tables S1 and S2) used for determining drugs of abuse in drinking water. Solid phase extraction (SPE) is the most commonly used sample preparation method to concentrate the sample and to remove undesired interferences [15]. It is crucial to utilise an analytical method which could offer both selectivity and sensitivity, when considering the determination of trace levels of such contaminants. Liquid chromatographytandem mass spectrometry (LC-MS/MS), gas chromatographymass spectrometry (GC-MS) and capillary electrophoresis-ultraviolet detector (CE-UV) have been previously used [16,17]. All of these techniques are able to determine trace levels (ng/L), which can be used to assess the occurrence and removal efficiencies of drugs of abuse during water treatment methods.

\section{Analytical methodology}

Analytical methodologies for the detection and quantification of drugs of abuse in drinking water normally include a sample preparation step followed by analysis using chromatography and mass spectrometry based techniques for further separation and detection. These methods are summarised in Table S1 and S2.

\subsection{Sample collection}

As shown in Table S1, drinking water is usually collected as grab samples. This sampling method where the sample represents the water conditions at the time of collection (grab sampling) is better for detecting the changes of analyte concentrations during a shortterm period, but not suitable for obtaining the time-weighted average (TWA) information [18]. By contrast, passive sampling can accumulate the compounds of interest dissolved in the water into a receiving phase through diffusion or permeation and thus provide TWA concentrations over a long-term period [18]. This is useful for assessing the overall impact of water contaminants on human health with long term exposure [19]. The receiving phase of passive sampler is similar to SPE sorbent and its chemistry is selected based on the target compounds as discussed later in Section 2.2. However, only a few publications $[20,21]$ reported the use of passive samplers for the collection of drinking water. This could be due to the relatively higher cost of equipment and extensive calibration studies that are required to evaluate the sampling rates of analytes [11,22,23].

After sample collection, drinking water is mainly stored in glass bottles at low temperature $\left(-20^{\circ} \mathrm{C}\right.$ to $\left.8^{\circ} \mathrm{C}\right)$, except some authors reported the use of plastic bottles [24-27]. Baker and KasprzykHordern [28] suggested all glassware used to store the sample should be silanised in order to avoid the adsorption of drugs of abuse, which can result in the loss of compounds and affect the recoveries, especially in trace analysis [29]. Aqueous solutions can deprotonate silanol groups leaving a negative charge on the glassware surface resulting in cation exchange sites for the interaction with basic compounds [30]. A study carried out on the analysis of drugs of abuse from surface and waste waters reported a higher recovery using silanised glassware [28]. This was prominent for basic compounds such as amphetamines, ketamine and norketamine as they are attracted to the negative charged surface [28]. For example, ketamine recovery was around $20 \%$ when vials were unsilanised, compared to $84 \%$ when silanised vials were used. Thus, the use of silanised glassware or the deactivation of glassware by rinsing with $5 \%$ dimethylchlorosilane in toluene, followed by toluene and then methanol is recommended [31].

In order to accurately detect the concentrations of drugs of abuse in drinking water at the time of collection, some authors add ascorbic acid and sodium thiosulfate to remove residual chlorine [32] in order to prevent further degradation by chlorination $[2,6,24,27,33-37]$. Sodium azide has also been added to stop bacterial degradation $[2,33]$. Then the sample is often filtered through a glass fibre or membrane filter prior to SPE. At this point samples are either extracted immediately or stored for 12 hrs to 7 days, during which period analytes of interest may start degrading. Therefore, there is a need for further studies in relation to the stability of analytes in the matrix itself.

\subsection{Sample preparation}

SPE is used for the extraction of drugs of abuse from drinking water as shown in Table S1. The majority of studies used reversed phase sorbents, including Oasis HLB, PLRP-s, Strata-X polymeric reversed phase, Poly-Sery HLB and HySphere Resin GP, as they are developed for the extraction of neutral, acidic and basic compounds from polar matrices. This is very important for the simultaneous analysis of drugs of abuse from different classes including amphetamines, benzodiazepines, cannabinoids, cocainics, dissociative anaesthetics, hallucinogenic substances and opioid analgesics. Authors reported moderate to high recoveries (50-132\%), indicating reversed phase sorbents can extract most of the target analytes from drinking water. However, recoveries are variable between different classes of compounds (75-99\% for amphetamines, $50-114 \%$ for benzodiazepines, $62-111 \%$ cannabinoids, $85-116 \%$ for cocainics, $83-93 \%$ for dissociative anaesthetics, $77-124 \%$ for hallucinogenic substances and 60 $132 \%$ for opioid analgesics). High recoveries were obtained (82$104 \%$ ) using Oasis MCX, a mixed-mode cation-exchange sorbent, for the extraction of basic compounds such as amphetamines, benzodiazepines, cocainics, dissociative anaesthetics and opioid analgesics from drinking water [21,38,39].

SPE centres more on the removal of undesired interferences from waste and surface waters in order to reduce matrix effects, as matrix components are responsible for adverse effect on analyte during injection in GC-MS or ion suppression/enrichment during ionisation process in LC-MS [40]. This can consequently impact on accuracy, precision and reproducibility $[40,41]$. For drinking water analysis, it is less of an issue because the matrix is cleaner than waste and surface waters, but removing matrix components is still of importance. In addition, internal standards should be added into water samples before extraction to compensate for matrix effect [42]. Some authors recommend using a matrix matched standard addition method for quantification $[43,44]$ and Cimetiere, et al. [44] reported improvements in the determination of pharmaceuticals in drinking water using this method.

The use of SPE can also concentrate the water samples in order to increase method sensitivity. Boleda, et al. [24] and Sun, et al. [45] both used Oasis HLB sorbent to extract codeine from drinking water. They reported similar recoveries (96 and 99.7\%) but their quantification limit (LOQ) was lowered to $0.03 \mathrm{ng} / \mathrm{L}$ [45] due to 2000 -fold enrichment factor as opposed to $0.5 \mathrm{ng} / \mathrm{L}$ [24] with enrichment factor of 400 . Thus, acquiring a high enrichment factor is more important as drugs of abuse are present in drinking water at trace levels (sub $\mathrm{ng} / \mathrm{L}$ ) and this is possible by the use of SPE as shown in Table S1. 


\subsection{Analytical techniques}

LC-MS/MS has been widely reported for detecting and quantifying drugs of abuse in drinking water (Table S2), with some exceptions [38]. In this case the authors used GC-MS to detect diazepam and its metabolite nordiazepam from drinking water. The advantages of GC-MS are (i) this technique is less expensive than LC-MS/MS and thus more widely available in laboratories and (ii) the mass spectra can be compared between different instruments and to reference databases for identification [53]. However, the drawback of GC-MS is the need of chemical derivatisation [53] as most drugs of abuse are polar compounds [54] and are less volatile [55,56]. The analysis of drugs of abuse by LC-MS/MS does not need derivatisation and hence why LC-MS/MS is the preferred method.

Botello, et al. [17] reported an alternative analytical method for the analysis of four drugs of abuse in drinking water using in-line SPE in combination with CE-UV. This method was reported to be environmentally friendly due to the low volume of organic solvent used for analysis. However, it is not suitable for compounds without chromophores and this method suffers from low sensitivity. The lower limit of detection (LOD) of 2-ethylidene-1,5-dimethyl-3,3diphenylpyrrolidine (EDDP), cocaine, codeine and 6-acetylmorphine ranged between 70 and $260 \mathrm{ng} / \mathrm{L}$, which are significantly higher than those reported using LC-MS/MS (0.02-17 ng/L) (Table S2).

LC-MS/MS methods as reported in Table S2 used reversedphase chromatography. Electrospray ionisation is often used as it is more efficient for polar and ionisable compounds than atmospheric pressure chemical ionisation and more sensitive for alkaloids when using selected reaction monitoring (SRM) [57,58]. Flow rates below $1 \mathrm{~mL} / \mathrm{min}$ and $\mathrm{pH}$ values ranging from 3.2-4.7 are applied to improve the ionisation of drugs of abuse [59]. The choice of ionisation mode (i.e. positive and negative) is decided by the chemical properties of target analytes. The analysis of drugs of abuse is commonly carried out in positive mode. As an exception, cannabinoids have been analysed in both positive and negative modes. The LOQs were reported in the range of 0.1 and $6.81 \mathrm{ng} / \mathrm{L}$ in negative mode $[25,26]$ as compared to the significantly higher values in positive mode (7-50 ng/L) [24,34].

Tandem mass spectrometry is dominantly used as this kind of analyser combines two or more mass-to-charge ratio separation devices of the same or different types. This results in faster acquisition time and higher resolving power when compared to a single mass analyser [60]. Triple quadrupole (QqQ) and hybrid triple quadrupole-linear ion trap (QqQ-LIT) have been used for the analysis of drugs of abuse in drinking water. Although selected ion monitoring was reported in one study [61], SRM is most commonly utilised as acquisition mode, as it can fragment the precursor ion of target compound and then monitor the unique product ions and therefore is reported to increase selectivity [62]. Two SRM transitions (precursor ion/product ion) are normally monitored for each analyte in order for reliable quantification and confirmation. The precursor ions are their protonated molecular ions in positive ionisation and deprotonated molecular ions in negative ionisation (Table S2). Two most abundant product ions are then selected for each analyte. However, the selected ions are variable between different methods as shown in Table S2, as collision energy and gas pressure used may not be the same from instrument to instrument [63]. This causes difficulty in building a LC-MS library/database.

Recently, the hybrid linear ion trap/orbitrap mass spectrometer (LIT-Orbitrap), a high resolution mass analyser type, has been utilised to analyse drugs of abuse in drinking water. Rodayan, et al. [21] reported similar or higher LODs and LOQs using LIT-Orbitrap when compared to QqQ and QqQ-LIT (Table S2) for the determination of amphetamines, cocainics, opioids and one dissociative anaesthetic in drinking water. Owing to this, LIT-Orbitrap might not be the best choice for quantification but would certainly add value to elucidate the molecular formulae and structures of the suspected or unknown molecules, which is more suitable for suspect screening and non-target screening. This is because the hybrid system is able to measure the masses of molecules accurately to several decimal places and allows the differentiation between two compounds which would be identical if a low resolution instrument such as QqQ was used. LIT-Orbitrap has been used by Kiwa Water Research Institute [64] for the screening of surface, ground and drinking waters in search of accurate masses corresponding to target pharmaceuticals, benzotriazoles and drugs of abuse as well as unknown compounds. This method can sensitively and reliably propose tentative elemental composition of an unknown compound which is of importance when screening for emerging drugs of abuse such as novel psychoactive substances (NPSs).

\section{Occurrence of drugs of abuse in drinking water}

Drinking water refers to water that has undergone drinking water treatment and is ready for human consumption. Samples are normally taken from the outlets of DWTPs via passive or grab sampling or directly from the taps in public places or private residences. Recent literature indicates that drugs of abuse (amphetamines, benzodiazepines, cannabinoids, cocainics, dissociative anaesthetics and opioid analgesics) have been determined in drinking water at concentrations in the ng/L range in Europe, America and Asia. Results from these studies are summarised in Table 1, including the frequency of determination, which is calculated by dividing the number of quantified samples (>LOQ) by the number of total samples.

The frequency of determination of drugs of abuse in drinking water is limited, only 22 drugs of abuse and six metabolites (Table 1) have been detected at the concentration range of 0.1 and $562 \mathrm{ng} / \mathrm{L}$ in Europe, America and Asia. Boleda, et al. [24] analysed drinking water from around the world, more than half the samples were from Spain and the others from seven European countries (Austria, France, Germany, Iceland, Slovakia, Switzerland and the UK), seven Latin American countries (Argentina, Brazil, Chile, Colombia, Panama, Peru and Uruguay) and Japan. This is the only study, where drinking water samples from different countries have been analysed.

Five amphetamines [amphetamine, methamphetamine, 3,4methylenedioxyamphetamine (MDA), methylenedioxyethylamphetamine (MDEA) and 3.4-methylenedioxymethamphetamine (MDMA)] were quantified in a few samples from Spain and Latin American countries at trace levels $(0.2-3.13 \mathrm{ng} / \mathrm{L}$ ) (Table 1$)$. These low concentrations could be due to the high removal efficiency as a result of using ultraviolet (UV) disinfection, reverse osmosis and ozonation $\left(\mathrm{O}_{3}\right)$ at DWTPs (96-100\%) [6,51]. Only a higher concentration of MDA $(6.7 \mathrm{ng} / \mathrm{L})$ was reported in the drinking water of Canada, which could be associated to less efficient water treatment methods (clarification and post-chlorination) [21]. Compared to amphetamines, benzodiazepines were present in drinking water at higher concentrations (0.1$562 \mathrm{ng} / \mathrm{L}$ ) in China, Italy, Spain, the UK and the USA. Alprazolam, diazepam and temazepam were frequently determined in most samples as shown in Table 1 . These results are probably due to their extensive, daily medical use as anti-anxiety pharmaceuticals [46,50]. Lorazepam was reported at $562 \mathrm{ng} / \mathrm{L}$ in Spain [47], which is much higher concentration than other benzodiazepines $(0.1-23.5 \mathrm{ng} / \mathrm{L})$. The mean concentration in drinking water (562 ng/L) was higher as compared to surface water $(167 \mathrm{ng} / \mathrm{L})$ collected from the same cities [47]. This could be associated with the conversion of the glucuronide metabolite of lorazepam to the parent compound during water treatment $[47,65]$.

The presence of cannabinoids, $\Delta^{9}$-tetrahydrocannabinol (THC) and two metabolites 11-hydroxy- $\Delta^{9}$-tetrahydrocannabinol (OH-THC) and 11-nor-9-carboxy- $\Delta^{9}$-tetrahydrocannnabinol (THC-COOH), in drinking water was only reported in Spain $(0.49$ to $5.53 \mathrm{ng} / \mathrm{L})$. The low concentrations of cannabinoids do not correlate with their high consumption rate [66]. Cannabinoids being less soluble in water could 
Table 1

Concentrations of drugs of abuse and their metabolites in drinking water

\begin{tabular}{|c|c|c|c|c|c|c|}
\hline Compound & Country & Study Period & $\begin{array}{l}\text { Sample } \\
\text { Number }\end{array}$ & Concentration (ng/L) & $\begin{array}{l}\text { Determination } \\
\text { Frequency (\%) }\end{array}$ & Refs \\
\hline \multicolumn{7}{|l|}{ Amphetamines } \\
\hline Amphetamine & Spain & 2008-2009 & 50 & $<1^{\mathrm{j}} ; 1.7^{\mathrm{h}}$ & 2.0 & [24] \\
\hline \multirow[t]{3}{*}{ MDA } & Canada & 2012 & $3^{k}$ & $6.7 \pm 1.1^{g}$ & n.r. & [21] \\
\hline & Latin America d & $2008-2009$ & 9 & $<0.8^{\mathrm{j}} ; 1.3^{\mathrm{h}}$ & 44.4 & [24] \\
\hline & Spain & 2008-2009 & 50 & $<0.8^{\mathrm{j}} ; 0.9^{\mathrm{h}}$ & 2.0 & [24] \\
\hline \multirow[t]{2}{*}{ MDEA } & Latin America d & $2008-2009$ & 9 & $<0.2^{\mathrm{j}} ; 0.4^{\mathrm{h}}$ & 22.2 & [24] \\
\hline & Spain & $2008-2009$ & 50 & $<0.2^{\mathrm{j}} ; 0.6^{\mathrm{h}}$ & 4.0 & [24] \\
\hline \multirow[t]{3}{*}{ MDMA } & Latin America d & 2008-2009 & 9 & $<0.2^{\mathrm{j}} ; 0.4^{\mathrm{h}}$ & 44.4 & [24] \\
\hline & Spain & 2010 & 3 & 1.51 & 33.3 & [25] \\
\hline & Spain & 2013 & 28 & 1.47 & 3.6 & [27] \\
\hline \multirow[t]{3}{*}{ Methamphetamine } & Latin America d & $2008-2009$ & 9 & $<0.5^{\mathrm{j}} ; 0.6^{\mathrm{h}}$ & 11.1 & [24] \\
\hline & Spain & 2008-2009 & 50 & $<0.5^{\mathrm{j}} ; 1.4^{\mathrm{h}}$ & 4.0 & [24] \\
\hline & Spain & 2013 & 28 & 3.13 & 3.6 & [27] \\
\hline \multicolumn{7}{|l|}{ Benzodiazepines } \\
\hline \multirow[t]{2}{*}{ Alprazolam } & China & 2014 & 5 & $2.30-2.60^{\mathrm{i}} ; 2.42 \pm 0.13^{\mathrm{g}}$ & 100.0 & {$[46]$} \\
\hline & Spain & $2008-2009$ & 75 & 11 & 1.3 & [47] \\
\hline Bromazepam & China & 2014 & 5 & 0.4 & 20.0 & [46] \\
\hline \multirow[t]{4}{*}{ Diazepam } & China & 2014 & 5 & $0.60-3.20^{\mathrm{i}} ; 1.94 \pm 1.17^{\mathrm{g}}$ & 100.0 & [46] \\
\hline & Italy & n.r. & 4 & $0.2-23.5^{\mathrm{i}} ; 14.43 \pm 12.48^{\mathrm{g}}$ & 75.0 & [48] \\
\hline & UK & n.r. & n.r. & $10^{\mathrm{h}}$ & n.r. & [49] \\
\hline & USA & 2006-2007 & 19 & $<0.25-0.33^{\mathrm{i}} ; 0.33^{\mathrm{h}}$ & 5.3 & [2] \\
\hline Lorazepam & Spain & $2008-2009$ & 75 & $562^{g}$ & 2.7 & [47] \\
\hline Temazepam & China & 2014 & 5 & $<0.1-0.6^{\mathrm{i}} ; 0.24 \pm 0.23^{\mathrm{g}}$ & 80.0 & [46] \\
\hline Cannabinoids & & & & & & \\
\hline THC & Spain & 2010 & 3 & 5.53 & 33.3 & [25] \\
\hline $\mathrm{OH}-\mathrm{THC}{ }^{\mathrm{a}}$ & Spain & 2010 & 3 & 0.49 & 33.3 & [25] \\
\hline $\mathrm{THC}-\mathrm{COOH}^{\mathrm{a}}$ & Spain & 2012 & 8 & $1^{\mathrm{g}}$ & 12.5 & [26] \\
\hline Cocainics & & & & & & \\
\hline Cocaine & Canada & 2012 & $3^{k}$ & $4.30 \pm 0.73^{g}$ & n.r. & [21] \\
\hline & Europe $^{e}$ & 2008-2009 & 15 & $0.1^{\mathrm{g}}$ & n.r. & [24] \\
\hline & Japan & $2008-2009$ & 3 & $<0.1^{\mathrm{j}}$ & n.r. & [24] \\
\hline & Latin America d & $2008-2009$ & 9 & $0.6^{g}$ & n.r. & [24] \\
\hline & Spain & $2008-2009$ & 50 & $0.4^{\mathrm{g}} ; 2.3^{\mathrm{h}}$ & 66.0 & [24] \\
\hline & Spain & 2012 & 6 & 1.61 & 16.7 & [50] \\
\hline & Spain & 2013 & 28 & $0.11-85.67^{i}$ & 25.0 & [27] \\
\hline Benzoylecgonine ${ }^{b}$ & Canada & 2012 & $3^{k}$ & $10.0 \pm 2.8^{g}$ & n.r. & [21] \\
\hline & Canada & 2012 & $2^{1}$ & $9.85^{\mathrm{g}} ; 9.0-10.7^{\mathrm{i}}$ & 100.0 & [21] \\
\hline & Europe $\mathrm{e}^{\mathrm{e}}$ & 2008-2009 & 15 & $0.2^{g}$ & n.r. & [24] \\
\hline & Latin America d & $2008-2009$ & 9 & $4.5^{g}$ & n.r. & [24] \\
\hline & Spain & 2007 & 24 & $3-130^{i}$ & 91.7 & [6] \\
\hline & Spain & 2008-2009 & 50 & $0.4^{\mathrm{g}} ; 3.1^{\mathrm{h}}$ & 34.0 & [24] \\
\hline & Spain & 2009 & n.r. & $1.5^{\mathrm{h}}$ & n.r. & [51] \\
\hline & Spain & 2013 & 28 & $0.11-52.73^{i}$ & 50.0 & [27] \\
\hline & UK & 2010 & 94 & $1.12-3.51^{\mathrm{i}} ; 2.53 \pm 0.85^{\mathrm{g}}$ & 9.6 & [20] \\
\hline Cocaethylene $^{b}$ & Europe ${ }^{\mathrm{e}}$ & 2008-2009 & 15 & $<0.1^{\mathrm{j}}$ & n.r. & [24] \\
\hline & Latin America d & $2008-2009$ & 9 & $<0.1^{\mathrm{j}} ; 0.4^{\mathrm{h}}$ & n.r. & [24] \\
\hline & Spain & $2008-2009$ & 50 & $0.2^{\mathrm{g}} ; 0.9^{\mathrm{h}}$ & 28.0 & [24] \\
\hline Dissociative Anaest & & & & & & \\
\hline Ketamine & Canada & 2012 & $3^{k}$ & $15.0 \pm 3.1^{\mathrm{g}}$ & n.r. & {$[21]$} \\
\hline & Canada & 2012 & $2^{1}$ & $15^{\mathrm{g} ;} 14-16^{\mathrm{i}}$ & 100.0 & [21] \\
\hline Opioid Analgesics & & & & & & \\
\hline Acetylcodeine & Canada & 2012 & $2^{1}$ & $5.7^{\mathrm{g}} ; 5.3^{-6.1^{\mathrm{i}}}$ & 100.0 & {$[21]$} \\
\hline Codeine & Canada & 2012 & $3^{k}$ & $44.0 \pm 3.5^{g}$ & n.r. & [21] \\
\hline & Canada & 2012 & $2^{1}$ & $<2.3^{\mathrm{j}}$ & 0.0 & [21] \\
\hline & USA & 2003 & 12 & $30^{\mathrm{h}}$ & 8.3 & [52] \\
\hline Dihydrocodeine & Canada & 2012 & $3^{k}$ & $5.7 \pm 1.5^{g}$ & n.r. & [21] \\
\hline Fentanyl & Canada & 2012 & $3^{k}$ & $12.0 \pm 1.7^{\mathrm{g}}$ & n.r. & [21] \\
\hline & Canada & 2012 & $2^{1}$ & $11.5^{\mathrm{g}} ; 11-12^{\mathrm{i}}$ & 100.0 & [21] \\
\hline & Spain & $2008-2009$ & 50 & $<1^{\mathrm{j}} ; 1.4^{\mathrm{h}}$ & 2.0 & [24] \\
\hline Heroin & Canada & 2012 & $3^{\mathrm{k}}$ & $<4.6^{j}$ & 0.0 & [21] \\
\hline & Canada & 2012 & $2^{1}$ & $<4.6^{\mathrm{j}}$ & 0.0 & [21] \\
\hline Methadone & Europe $\mathrm{e}^{\mathrm{e}}$ & $2008-2009$ & 15 & $0.1^{g}$ & n.r. & [24] \\
\hline & Latin America d & 2008-2009 & 9 & $0.2^{\mathrm{g}}$ & n.r. & [24] \\
\hline & Spain & $2007-2008$ & 18 & $0.1-1.7^{i}$ & 61.1 & [34] \\
\hline & Spain & $2008-2009$ & 50 & $0.2^{\mathrm{g}} ; 2.7^{\mathrm{h}}$ & 18.0 & [24] \\
\hline & Spain & 2010 & 3 & 0.99 & 33.3 & [25] \\
\hline & Spain & 2013 & 28 & $0.11-0.31^{\mathrm{i}} ; 0.18 \pm 0.09^{\mathrm{g}}$ & 14.3 & [27] \\
\hline EDDP $\mathrm{c}$ & Europe $^{\mathrm{e}}$ & $2008-2009$ & 15 & $0.4^{g}$ & n.r. & [24] \\
\hline & Japan & $2008-2009$ & 3 & $0.1^{g}$ & n.r. & [24] \\
\hline & Latin America d & 2008-2009 & 9 & $0.4^{\mathrm{g}}$ & n.r. & [24] \\
\hline & Spain & $2007-2008$ & 18 & $0.2-2.9^{\mathrm{i}}$ & 77.8 & [34] \\
\hline & Spain & 2008-2009 & 50 & $0.4^{\mathrm{g}} ; 3.5^{\mathrm{h}}$ & 86.0 & [24] \\
\hline & Spain & 2013 & 28 & $0.20-1.41^{\mathrm{i}} ; 0.81 \pm 0.86^{\mathrm{g}}$ & 7.1 & [27] \\
\hline & & & & & (con & page) \\
\hline
\end{tabular}


Table 1 (continued)

\begin{tabular}{|c|c|c|c|c|c|c|}
\hline Compound & Country & Study Period & $\begin{array}{l}\text { Sample } \\
\text { Number }\end{array}$ & Concentration (ng/L) & $\begin{array}{l}\text { Determination } \\
\text { Frequency (\%) }\end{array}$ & Refs \\
\hline Morphine & Canada & 2012 & $3^{k}$ & $6.4 \pm 4.1^{\mathrm{g}}$ & n.r. & [21] \\
\hline 6-Acetylmorphine ${ }^{\mathrm{f}}$ & Canada & 2012 & $2^{1}$ & $6.7^{\mathrm{g}} ; 5.7-7.7^{\mathrm{i}}$ & 100.0 & [21] \\
\hline Oxycodone & Canada & 2012 & $3^{k}$ & $5.10 \pm 0.75^{g}$ & n.r. & [21] \\
\hline Tramadol & Canada & 2012 & $3^{k}$ & $5.4 \pm 1.4^{g}$ & n.r. & [21] \\
\hline
\end{tabular}

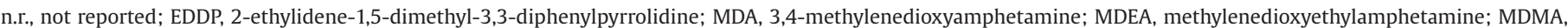

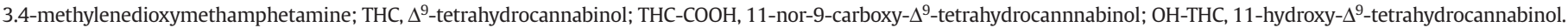

a Metabolite of THC.

b Metabolite of cocaine.

Metabolite of methadone.

d Includes Argentina, Brazil, Chile, Colombia, Panama, Peru and Uruguay.

e Includes Austria, France, Germany, Iceland, Slovakia, Switzerland and the UK.

f Metabolite of morphine.

g Mean concentration.

h Maximum concentration.

i Concentration range ( $\min -\max$ ).

${ }^{\mathrm{j}}$ Mean concentration below quantification limit but above detection limit.

k Sample numbers of passive sampling.

1 Sample numbers of grab sampling.

have resulted in the partition to solids depending on their physiochemical properties ( $\log \mathrm{K}_{\mathrm{ow}}>5$ ) [50]. This is evidenced by the detection of THC metabolites (THC-COOH and OH-THC) in suspended solids in raw wastewater and activated sludge [67]. On the contrary, cocaine and its two metabolites (benzoylecgonine and cocaethylene) were present in drinking water from different countries, including Canada, Japan, European and Latin American countries. The concentration of benzoylecgonine (0.11-10.0 ng/L) was higher than cocaine (0.1-4.3 ng/L) and this can be explained by its metabolism. Cocaine is mainly excreted as benzoylecgonine (20-60\%) and only $1-15 \%$ is eliminated in the urine unchanged [16]. Cocaethylene, which is a cocaine metabolite excreting as $0.7 \%$ in the presence of ethanol [16], was quantified from Spain and Latin American countries with the highest concentration of $0.9 \mathrm{ng} / \mathrm{L}$. This has also been positively identified in other European countries $(<0.1 \mathrm{ng} /$ L), indicating a high level of alcohol consumption [50]. Significantly higher concentrations of cocaine and benzoylecgonine (85.67 and $52.73 \mathrm{ng} / \mathrm{L}$, respectively) were reported from the Aranjuez of Spain [27] with the concentration ratio of 1.62, which is considered as an abnormal ratio $(>0.75)$, suggesting the measured value may not result from human consumption only [68]. Therefore, this could be due to the disposal of cocaine at/near the sampling site as trace amounts of cocaine (0.12-1.21 ng/L) and benzoylecgonine (1.13-1.55 ng/L) were determined in a water sample treated by the same DWTP (Tajo, Spain) but was collected from a different sampling site (Titulcia, Spain) [27]. In addition to this, the highest concentration of benzoylecgonine $(130 \mathrm{ng} / \mathrm{L})$ was determined in drinking water in the north-eastern region of Spain [6] despite high removal efficiency of the DWTP (89\%). This could be explained by highly contaminated raw water (770 ng/ L) that was used for drinking water production.

Among nine opioids and two metabolites, the highest concentration in drinking water was reported for codeine at the concentrations of 30 and $44 \mathrm{ng} / \mathrm{L}$ in the USA and Canada. This is not surprising as codeine is a prescription medication that is also contained in nonsteroidal anti-inflammatory drugs such as aspirin and ibuprofen [69]. The presence of methadone in drinking water from European and Latin American countries ranged between 0.1$2.7 \mathrm{ng} / \mathrm{L}$ while its metabolite EDDP was also reported from Japan. Rodayan, et al. [21] reported heroin $(<4.6 \mathrm{ng} / \mathrm{L})$ and acetylcodeine $(5.3-6.1 \mathrm{ng} / \mathrm{L})$ in the drinking water from Ontario, Canada. The presence of acetylcodeine indicates the illicit use of heroin in the province of Ontario. This is because acetylcodeine is an impurity of manufacturing process [70]. Oxycodone was also found in drinking water
(5.1 ng/L), even after its ban in Ontario in 2012 [21]. This could be owing to the easy access of oxycodone via online stores. Subsequent to this ban, the increase use of fentanyl and ketamine was evident from drinking water analysis (11-12 and 14-16 ng/L, respectively) [21].

\section{Removal efficiencies of drugs of abuse from drinking water treatment plants}

Even though after treatment, low concentrations of drugs of abuse are still being detected in drinking water (Table 1). Therefore, there are concerns that current drinking water treatment methods do not completely remove such contaminants. The removal efficiencies of drugs of abuse in DWTPs have been reported in some studies $[6,21,34,35,51]$ and are summarised in Table 2 .

Generally, raw water undergoes several processes to produce drinking water. Chlorine gas, chloramines and ultraviolet light are applied to water for the disinfection of microorganisms [71]. Clarification, normally including coagulation, flocculation, sedimentation and sand filtration, are used to remove suspended sediments and dissolved organic carbon [52,72]. Some advanced drinking water treatment processes, such as $\mathrm{O}_{3}$, ultrafiltration, reverse osmosis and granular activated carbon (GAC), also remove organic and inorganic contaminants from water [71]. The removal efficiency of drugs of abuse depends on the applied water treatment methods. As shown in Table 2, advanced water treatments proved to be an efficient way to remove drugs of abuse from drinking water. For example, $\mathrm{O}_{3}$ and GAC treatments resulted in much better removal efficiencies for MDA, cocaine, benzoylecgonine, ketamine, codeine, fentanyl and morphine (89-100\%) [6,34,35,51], compared to the range of $-18 \%$ and $49 \%$ when using disinfection and clarification processes [21]. Ultrafiltration and reverse osmosis were able to remove MDMA, cocaine, benzoylecgonine, norbenzoylecgonine, ketamine, codeine, norcodeine, methadone and EDDP with the efficiencies between 97\% and 99\% [51]. In contrast, using disinfection and clarification, low removal efficiencies ( $-39 \%$ to $49 \%$ ) have been reported for MDA, cocaine, benzoylecgonine, ketamine, codeine, dihydrocodeine, fentanyl, morphine, oxycodone and tramadol [21]. This indicates that the treatment method may influence the level of drugs of abuse present in drinking water.

In general, some drugs of abuse can still remain even after advanced water treatments, resulting in their presence in drinking water at trace levels as shown in Table 2. For instance, Boleda, 
Table 2

Removal efficiencies of drugs of abuse and their metabolites during drinking water treatment

\begin{tabular}{|c|c|c|c|c|c|}
\hline Compounds & $\begin{array}{l}\text { DWTP } \\
\text { Routes e }\end{array}$ & $\begin{array}{l}\text { Removal } \\
\text { Efficiency (\%) }\end{array}$ & $\begin{array}{l}\text { Lethal } \\
\text { Dose }^{f}(g)\end{array}$ & $\begin{array}{l}\text { Therapeutic } \\
\text { Dose }^{f}(g)\end{array}$ & Refs \\
\hline \multicolumn{6}{|l|}{ Amphetamines } \\
\hline Amphetamine & 1 & 100 & 0.2 & $0.02-0.1$ & {$[6]$} \\
\hline \multirow[t]{2}{*}{ MDA } & 1 & 100 & 0.5 & - & [6] \\
\hline & 4 & 7 & & & [21] \\
\hline \multirow[t]{3}{*}{ MDMA } & 1 & 100 & 0.3 & $0.08-0.2$ & [6] \\
\hline & 1 & 96 & & & [51] \\
\hline & 2 & 99 & & & [51] \\
\hline Methamphetamine & 1 & 100 & 1 & $0.0025-0.025$ & [6] \\
\hline \multicolumn{6}{|l|}{ Benzodiazepines } \\
\hline Bromazepam & 1 & $>99$ & - & $0.003-0.018$ & [35] \\
\hline Diazepam & 1 & $>99$ & - & - & [35] \\
\hline Oxazepam & 1 & 97 & - & - & [35] \\
\hline \multicolumn{6}{|l|}{ Cannabinoids } \\
\hline THC & 3 & $>99$ & - & - & [34] \\
\hline THC-COOH ${ }^{a}$ & 3 & $>99$ & - & - & [34] \\
\hline \multicolumn{6}{|l|}{ Cocainics } \\
\hline \multirow[t]{4}{*}{ Cocaine } & 1 & 100 & 1.2 & - & {$[6]$} \\
\hline & 1 & 99 & & & [51] \\
\hline & 2 & $>99$ & & & [51] \\
\hline & 4 & -18 & & & [21] \\
\hline \multirow[t]{4}{*}{ Benzoylecgonine $^{b}$} & 1 & 89 & - & - & [6] \\
\hline & 1 & 96 & & & [51] \\
\hline & 2 & 99 & & & [51] \\
\hline & 4 & 14 & & & [21] \\
\hline \multirow[t]{2}{*}{ Norbenzoylecgonine $^{b}$} & 1 & 96 & - & - & [51] \\
\hline & 2 & 99 & & & [51] \\
\hline \multicolumn{6}{|c|}{ Dissociative Anaesthetics } \\
\hline \multirow[t]{3}{*}{ Ketamine } & 1 & 92 & - & - & {$[51]$} \\
\hline & 2 & 98 & & & [51] \\
\hline & 4 & 49 & & & [21] \\
\hline \multicolumn{6}{|l|}{ Opioid Analgesics } \\
\hline \multirow[t]{4}{*}{ Codeine } & 1 & $>99$ & 0.8 & $0.03-0.06$ & [51] \\
\hline & 2 & $>99$ & & & [51] \\
\hline & 3 & $>99$ & & & [34] \\
\hline & 4 & 25 & & & {$[21]$} \\
\hline \multirow[t]{3}{*}{ Norcodeine $^{c}$} & 1 & 89 & - & - & [51] \\
\hline & 2 & 97 & & & [51] \\
\hline & 3 & $>99$ & & & [34] \\
\hline Dihydrocodeine & 4 & -10 & 0.5 & $0.03-0.06$ & {$[21]$} \\
\hline \multirow[t]{2}{*}{ Fentanyl } & 3 & $>99$ & 0.002 & - & [34] \\
\hline & 4 & 0 & & & [21] \\
\hline \multirow[t]{3}{*}{ Methadone } & 1 & 99 & 0.05 & $0.0025-0.01$ & [51] \\
\hline & 2 & $>99$ & & & [51] \\
\hline & 3 & 91 & & & [34] \\
\hline \multirow[t]{3}{*}{ EDDP $^{\mathrm{d}}$} & 1 & $>99$ & - & - & [51] \\
\hline & 2 & $>99$ & & & [51] \\
\hline & 3 & 88 & & & [34] \\
\hline \multirow[t]{2}{*}{ Morphine } & 3 & $>99$ & 0.2 & $0.005-0.02$ & [34] \\
\hline & 4 & -2 & & & [21] \\
\hline Oxycodone & 4 & -3 & 0.5 & - & [21] \\
\hline Tramadol & 4 & -39 & - & $0.05-0.1$ & [21] \\
\hline
\end{tabular}

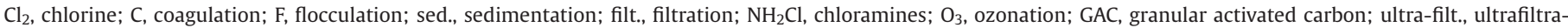
tion; UV, ultraviolet disinfection; RO, reverse osmosis; re-mine., remineralisation.

a Metabolite of THC.

b Metabolite of cocaine.

c Metabolite of codeine.

d Metabolite of methadone.

e $\mathbf{1}=\mathrm{Cl}_{2} \rightarrow \mathrm{C} \rightarrow \mathrm{F} \rightarrow$ sed. $\rightarrow$ filt. $\rightarrow \mathrm{O}_{3} \rightarrow \mathrm{GAC} \rightarrow \mathrm{Cl}_{2}$; $\mathbf{2}=\mathrm{Cl}_{2} \rightarrow \mathrm{C} \rightarrow \mathrm{F} \rightarrow$ sed. $\rightarrow$ filt. $\rightarrow$ ultra-filt. $\rightarrow$ UV $\rightarrow$ RO $\rightarrow$ re-mine. $\rightarrow \mathrm{Cl}_{2}$; $\mathbf{3}=\mathrm{Cl}_{2} \rightarrow \mathrm{C} \rightarrow \mathrm{F} \rightarrow$ filt. $\rightarrow \mathrm{O}_{3} \rightarrow \mathrm{GAC} \rightarrow \mathrm{Cl}_{2}$; $\mathbf{4}=\mathrm{C} \rightarrow \mathrm{F} \rightarrow$ filt. $\rightarrow \mathrm{Cl}_{2}$

f Moffat, et al., 2011 [73].

Galceran and Ventura [34] have evaluated the removal efficiencies of methadone and EDDP from a Spanish DWTP which used prechlorination, clarification, $\mathrm{O}_{3}, \mathrm{GAC}$ and post-chlorination. Both of these compounds were partiality removed ( $91 \%$ for methadone and $88 \%$ for EDDP) and therefore were detected in drinking water at trace levels. This is a cause of concern knowing the amount of water consumed by an individual on daily basis and the bioaccumulation of lipophilic compounds.

\section{Human health impacts}

Although drugs of abuse have been detected in drinking water at $\mathrm{ng} / \mathrm{L}$ range, these trace levels are not sufficient to induce acute toxic effects to humans as their concentrations are many orders of magnitude lower than those known to cause toxicological and pharmaceutical effects. The lethal and therapeutic doses are included in Table 2. As an example, cocaine has been measured at the 
maximum concentration of $85.67 \times 10^{-9} \mathrm{~g} / \mathrm{L}$ (i.e. $85.67 \mathrm{ng} / \mathrm{L}$ ) in drinking water [27]. Assuming that an individual drinks two litres of water per day, they would ingest an amount of cocaine equivalent to $171.34 \times 10^{-9} \mathrm{~g}$ and over a year $62.54 \times 10^{-6} \mathrm{~g}$, whereas the minimal lethal dose of cocaine is $1.2 \mathrm{~g}$ [74]. Our major concern is the longterm exposure of drugs of abuse via drinking water as some of these compounds are lipophilic and therefore can bio accumulate (e.g. cocaine and diazepam) [75-77]. Thus, their presence in drinking water can still be a potential threat to human health due to longterm exposure. Another consideration would be the possible reaction with other compounds which might cause synergistic or antagonistic effects. For instance, the combination of cocaine and heroin has been reported to amplify the effect of both drugs, therefore these compounds on their own (at a specific dose) may not be lethal but in combination could be toxic/lethal [78]. Therefore, it is impossible to rule out the potential toxicity or adverse effect of these compounds on human health via exposure to drinking water.

It has been already demonstrated that some drugs of abuse and their metabolites can also undergo different transformation during treatment processes resulting in products that may have higher toxicity compared to the parent compounds [37,79-81]. Such transformation products have been reported from the oxidation of EDDP via chlorination [81]. Although the human health impact of such transformation products and drugs of abuse in drinking water has not been reported, ecotoxicological impact of EDDP and its transformation products have already been reported in freshwater organisms [81]. This highlights the need for further research in assessing the human health impact due to the drugs of abuse in drinking water.

\section{Summary and conclusions}

This review includes an overview of sample preparation and analytical techniques used for the analysis of drugs of abuse in drinking water. SPE seems to be the most commonly used extraction method followed by LC-MS/MS analysis for the simultaneous detection of drugs of abuse. However, other mass spectrometers such as single quadrupole are much less used, but could be a good alternative as they are less expensive and their instrumental sensitivities are in general comparable to tandem mass spectrometers [60,82].

This review also summarises the occurrence and concentrations of drugs of abuse in drinking water from Europe, America and Asia, showing a global problem. These water contaminants are often found in drinking water at concentrations in $\mathrm{ng} / \mathrm{L}$ range. This review reveals that studies regarding the analysis of such compounds in drinking water are scarce. Most of these studies have been focussed in Spain, whereas relatively few studies are from other European, American and Asian countries. Currently there is no information available from Africa and Oceania. Therefore, there is a need to carry out more comprehensive and complementary studies to enable better comparison of data, prevalence and removal efficiencies of drugs of abuse from the DWTPs worldwide.

This review reveals that most research focuses on the detection of traditional drugs of abuse in drinking water, with a gap in knowledge on the detection of NPSs. NPSs such as cathinones, piperazines and synthetic cannabinoids are designed to mimic the pharmacological effects of known specific controlled drugs, such as amphetamines and cannabis, thus they have gained popularity among drug users and their consumption has grown [83]. Consequently, NPSs have been detected in waste water and surface water. For example, butylone, mephedrone, methcathinone, benzylpiperazine (BZP), 4-methoxyphenylpiperazine (4-MeOPP), 3-trifluoromethylphenylpiperazine (3-TFMPP) and ketamine have been detected in the waste and river waters from the UK [31,84].
However, only ketamine has been detected in drinking water so far [21]. Therefore, other NPSs needs to be investigated further, owing to their highly dynamic market, with newly identified NPSs reported globally (in 2013, 202 new NPSs were described and in 2014 a further 69 was recorded) [66]. This is not surprising as manufacturers continually carry out minor changes to their structures to evade legislation. High resolution mass spectrometry (as mentioned in Section 2.3) can be used to screen the drinking water samples, which could aid in the identification of new NPSs.

Although not included in current drinking water regulatory framework, it is important that drinking water companies and water regulatory bodies should be aware of the presence of drugs of abuse in drinking water. Further research on these contaminants needs to be carried out in order to gain valuable information on their occurrence and fate, as there is currently limited understanding of the human health impact with regards to their exposure via drinking water. In addition, incomplete removal of these compounds highlights the importance of future investment in more effective treatment processes and monitoring of drinking water with respect to these newer contaminants.

\section{Appendix: Supplementary material}

Supplementary data to this article can be found online at doi:10.1016/j.trac.2016.09.011.

\section{References}

[1] S. Ejaz, W. Akram, C.W. Lim, J.J. Lee, I. Hussain, Endocrine disrupting pesticides: a leading cause of cancer among rural people in Pakistan, Exp. Oncol. 26 (2004) 98-105.

[2] M.J. Benotti, R.A. Trenholm, B.J. Vanderford, J.C. Holady, B.D. Stanford, S.A. Snyder, Pharmaceuticals and endocrine disrupting compounds in U.S. drinking water, Environ. Sci. Technol. 43 (2009) 597-603, doi:10.1021/es801845a.

[3] C. Repice, M. Dal Grande, R. Maggi, R. Pedrazzani, Licit and illicit drugs in a wastewater treatment plant in Verona, Italy, Sci. Total Environ. 463-464 (2013) 27-34, doi:10.1016/j.scitotenv.2013.05.045.

[4] A. Jurado, E. Vàzquez-Suñé, J. Carrera, M. López de Alde, E. Pujades, D. Barceló, Emerging organic contaminants in groundwater in Spain: a review of sources, recent occurrence and fate in a European context, Sci. Total Environ. 440 (2012) 82-94, doi:10.1016/j.scitotenv.2012.08.029.

[5] R. Pal, M. Megharaj, K.P. Kirkbride, R. Naidu, Illicit drugs and the environment - a review, Sci. Total Environ. 463-464 (2012) 1079-1092, doi:10.1016/ j.scitotenv.2012.05.086.

[6] M. Huerta-Fontela, M.T. Galceran, F. Ventura, Stimulatory drugs of abuse in surface waters and their removal in a conventional drinking water treatment plant, Environ. Sci. Technol. 42 (2008) 6809-6816, doi:10.1021/es800768h.

[7] Drinking Water Inspectorate, The water supply (water quality) regulations 2010, Department for Environment Food and Rural Affairs, London. <http://dwi.defra .gov.uk/stakeholders/legislation/wsr2010wales.pdf>. 2010 (accessed 10.11.15).

[8] Drinking Water Inspectorate, What are the drinking water standards? Department for Environment Food and Rural Affairs, London. <http://dwi .defra.gov.uk/consumers/advice-leaflets/standards.pdf>. 2010 (accessed 10.11.15).

[9] E. Zuccato, S. Castiglioni, Illicit drugs in the environment, Philos. T. Roy. Soc. A 367 (2009) 3965-3978, doi:10.1098/rsta.2009.0107.

[10] T.H. Boles, M.J. Wells, Analysis of amphetamine and methamphetamine as emerging pollutants in wastewater and wastewater-impacted streams, J. Chromatogr. A 1217 (2010) 2561-2568, doi:10.1016/j.chroma.2010.01.014.

[11] A.L. van Nuijs, S. Castiglioni, I. Tarcomnicu, C. Postigo, M. López de Alda, H. Neels, et al., Illicit drug consumption estimations derived from wastewater analysis: a critical review, Sci. Total Environ. 409 (2011) 3564-3577, doi:10.1016/ j.scitotenv.2010.05.030.

[12] B. Petrie, R. Barden, B. Kasprzyk-Hordern, A review on emerging contaminants in wastewaters and the environment: current knowledge, understudied areas and recommendations for future monitoring, Water Res. 72 (2015) 3-27, doi:10.1016/j.watres.2014.08.053.

[13] S. González, R. López-Roldán, J. Cortina, Presence and biological effects of emerging contaminants in Llobregat River basin: a review, Environ. Pollut. 161 (2012) 83-92, doi:10.1016/j.envpol.2011.10.002.

[14] D.J. Lapworth, N. Baran, M.E. Stuart, R.S. Ward, Emerging organic contaminants in groundwater: a review of sources, fate and occurrence, Environ. Pollut. 163 (2012) 287-303, doi:10.1016/j.envpol.2011.12.034.

[15] Waters, Beginner's guide to SPE [solid-phase extraction]. <http:/ www.waters.com/waters/en_GB/Beginner\%27s-Guide-to-SPE-\%5BSolid -Phase-Extraction\%5D/nav.htm?cid=134721476\&lset=1\&locale=en_GB\& changedCountry $=\mathrm{Y}>$. 2015 (accessed 15.10.15). 
[16] S. Castiglioni, E. Zuccato, C. Chiabrando, R. Fanelli, R. Bagnati, Mass spectrometric analysis of illicit drugs in wastewater and surface water, Mass Spectrom. Rev. 27 (2008) 378-394, doi:10.1002/mas.20168.

[17] I. Botello, F. Borrull, C. Aguilar, M. Calull, Investigation of in-line solid-phase extraction capillary electrophoresis for the analysis of drugs of abuse and their metabolites in water samples, Electrophoresis 33 (2012) 528-535, doi:10.1002/ elps.201100199.

[18] T. Górecki, J. Namieśnik, Passive sampling, Trends Analyt. Chem. 21 (2002) 276-291, doi:10.1016/S0165-9936(02)00407-7.

[19] J. Namieśnik, B. Zabiegała, A. Kot-Wasik, M. Partyka, A. Wasik, Passive sampling and/or extraction techniques in environmental analysis: a review, Anal. Bioanal. Chem. 381 (2005) 279-301, doi:10.1007/s00216-004-2830-8.

[20] A.B.A. Boxall, S.C. Monteiro, R. Fussell, R.J. Williams, J. Bruemer, R. Greenwood, et al., Targeted monitoring for human pharmaceuticals in vulnerable source and final waters. <http://nora.nerc.ac.uk/17117/1/DWI70_2_231.pdf>. 2011 (accessed 26.07.16)

[21] A. Rodayan, S. Afana, P.A. Segura, T. Sultana, C.D. Metcalfe, V. Yargeau, Linking drugs of abuse in wastewater to contamination of surface and drinking water, Environ. Toxicol. Chem. 35 (2016) 843-849, doi:10.1002/etc.3085.

[22] B. Vrana, I.J. Allan, R. Greenwood, G.A. Mills, E. Dominiak, K. Svensson, et al., Passive sampling techniques for monitoring pollutants in water, Trends Analyt. Chem. 24 (2005) 845-868, doi:10.1016/j.trac.2005.06.006.

[23] Z. Zhang, A. Hibberd, J.L. Zhou, Analysis of emerging contaminants in sewage effluent and river water: comparison between spot and passive sampling, Anal. Chim. Acta 607 (2008) 37-44, doi:10.1016/j.aca.2007.11.024.

[24] M.R. Boleda, M. Huerta-Fontela, F. Ventura, M.T. Galceran, Evaluation of the presence of drugs of abuse in tap waters, Chemosphere 84 (2011) 1601-1607, doi:10.1016/j.chemosphere.2011.05.033.

[25] Y. Valcárcel, F. Martínez, S. González-Alonso, Y. Segura, M. Catalá, R. Molina, et al., Drugs of abuse in surface and tap waters of the Tagus River basin: heterogeneous photo-Fenton process is effective in their degradation, Environ. Int. 41 (2012) 35-43, doi:10.1016/j.envint.2011.12.006.

[26] E. Carmona, V. Andreu, Y. Picó, Occurrence of acidic pharmaceuticals and personal care products in Turia River Basin: from waste to drinking water, Sci. Total Environ. 484 (2014) 53-63, doi:10.1016/j.scitotenv.2014.02 .085 .

[27] A. Mendoza, B. Zonja, N. Mastroianni, N. Negreira, M. López de Alda, S. Pérez, et al., Drugs of abuse, cytostatic drugs and iodinated contrast media in tap water from the Madrid region (central Spain): A case study to analyse their occurrence and human health risk characterization, Environ. Int. 86 (2016) 107-118, doi:10.1016/j.envint.2015.11.001.

[28] D.R. Baker, B. Kasprzyk-Hordern, Critical evaluation of methodology commonly used in sample collection, storage and preparation for the analysis of pharmaceuticals and illicit drugs in surface water and wastewater by solid phase extraction and liquid chromatography-mass spectrometry, J. Chromatogr. A 1218 (2011) 8036-8059, doi:10.1016/j.chroma.2011.09.012.

[29] W. Ahrer, E. Scherwenk, W. Buchberger, Determination of drug residues in water by the combination of liquid chromatography or capillary electrophoresis with electrospray mass spectrometry, J. Chromatogr. A 910 (2001) 69-78, doi:10.1016/S0021-9673(00)01187-0.

[30] Water, Overcoming glass vial adsorption effects for trace analysis of basic compounds by LC/MS/MS. <http://www.waters.com/webassets/cms/library/ docs/720004027en.pdf>. 2011 (accessed 19.08.16).

[31] D.R. Baker, B. Kasprzyk-Hordern, Multi-residue analysis of drugs of abuse in wastewater and surface water by solid-phase extraction and liquid chromatography-positive electrospray ionisation tandem mass spectrometry, J. Chromatogr. A 1218 (2011) 1620-1631, doi:10.1016/j.chroma.2011.01.060.

[32] C. Zhang, Fundamentals of Environmental Sampling and Analysis, John Wiley and Sons, New Jersey, 2007

[33] B.J. Vanderford, S.A. Snyder, Analysis of pharmaceuticals in water by isotope dilution liquid chromatography/tandem mass spectrometry, Environ. Sci. Technol. 40 (2006) 7312-7320, doi:10.1021/es0613198.

[34] M.R. Boleda, M.T. Galceran, F. Ventura, Monitoring of opiates, cannabinoids and their metabolites in wastewater, surface water and finished water in Catalonia, Spain, Water Res. 43 (2009) 1126-1136, doi:10.1016/j.watres.2008 .11 .056 .

[35] M. Huerta-Fontela, M.T. Galceran, F. Ventura, Occurrence and removal of pharmaceuticals and hormones through drinking water treatment, Water Res. 45 (2011) 1432-1442, doi:10.1016/j.watres.2010.10.036.

[36] M. Gros, S. Rodríguez-Mozaz, D. Barceló, Fast and comprehensive multi-residue analysis of a broad range of human and veterinary pharmaceuticals and some of their metabolites in surface and treated waters by ultra-high-performance liquid chromatography coupled to quadrupole-linear ion trap tandem mass spectrometry, J. Chromatogr. A 1248 (2012) 104-121, doi:10.1016/ j.chroma.2012.05.084.

[37] M. Huerta-Fontela, O. Pineda, F. Ventura, M.T. Galceran, New chlorinated amphetamine-type-stimulants disinfection-by-products formed during drinking water treatment, Water Res. 46 (2012) 3304-3314, doi:10.1016/ j.watres.2012.03.029.

[38] A. Togola, H. Budzinski, Multi-residue analysis of pharmaceutical compounds in aqueous samples, J. Chromatogr. A 1177 (2008) 150-158, doi:10.1016/ j.chroma.2007.10.105

[39] M. Rabiet, A. Togola, F. Brissaud, J. Seidel, H. Budzinski, F. Elbaz-Poulichet, Consequences of treated water recycling as regards pharmaceuticals and drugs in surface and ground waters of a medium-sized Mediterranean catchment, Environ. Sci. Technol. 40 (2006) 5282-5288, doi:10.1021/es060528p.
[40] J. Hajšlová, J. Zrostlíková, Matrix effects in (ultra)trace analysis of pesticide residues in food and biotic matrices, J. Chromatogr. A 1000 (2003) 181-197, doi:10.1016/S0021-9673(03)00539-9.

[41] E. Chambers, D.M. Wagrowski-Diehl, Z. Lu, J.R. Mazzeo, Systematic and comprehensive strategy for reducing matrix effects in LC/MS/MS analyses, J. Chromatogr. B 852 (2007) 22-34, doi:10.1016/j.jchromb.2006.12.030.

[42] D. Hummel, D. Löffler, G. Fink, T.A. Ternes, Simultaneous determination of psychoactive drugs and their metabolites in aqueous matrices by liquid chromatography mass spectrometry, Environ. Sci. Technol. 40 (2006) 7321-7328, doi:10.1021/es061740w.

[44] N. Cimetiere, I. Soutrel, M. Lemasle, A. Laplanche, A. Crocq, Standard addition method for the determination of pharmaceutical residues in drinking water by SPE-LC-MS/MS, Environ. Technol. 34 (2013) 3031-3041, doi:10.1080/ 09593330.2013.800563.

[43] M. Petrović, M.D. Hernando, M.S. Díaz-Cruz, D. Barceló, Liquid chromatographytandem mass spectrometry for the analysis of pharmaceutical residues in environmental samples: a review, J. Chromatogr. A 1067 (2005) 1-14, doi:10.1016/j.chroma.2004.10.110.

[45] J. Sun, Q. Luo, D. Wang, Z. Wang, Occurrences of pharmaceuticals in drinking water sources of major river watersheds, China, Ecotoxicol. Environ. Saf. 117 (2015) 132-140, doi:10.1016/J.ecoenv.2015.03.032.

[46] M. Wu, J. Xiang, C. Que, F. Chen, G. Xu, Occurrence and fate of psychiatric pharmaceuticals in the urban water system of Shanghai, China, Chemosphere 138 (2015) 486-493, doi:10.1016/j.chemosphere.2015.07.002.

[47] S. Esteban, Y. Valcárcel, M. Catalá, M.G. Castromil, Psychoactive pharmaceutical residues in the watersheds of Galicia (Spain), Gac. Sanit. 26 (2012) 457-459, doi:10.1016/j.gaceta.2012.01.018.

[48] E. Zuccato, D. Calamari, M. Natangelo, R. Fanelli, Presence of therapeutic drugs in the environment, Lancet 355 (2000) 1789-1790, doi:10.1016/S01406736(00)02270-4.

[49] S. Mompelat, B. Le Bot, O. Thomas, Occurrence and fate of pharmaceutical products and by-products, from resource to drinking water, Environ. Int. 35 (2009) 803-814, doi:10.1016/j.envint.2008.10.008.

[50] A. Mendoza, J.L. Rodríguez-Gil, S. González-Alonso, N. Mastroianni, M. López de Alda, D. Barceló, et al., Drugs of abuse and benzodiazepines in the Madrid Region (Central Spain): Seasonal variation in river waters, occurrence in tap water and potential environmental and human risk, Environ. Int. 70 (2014) 76-87, doi:10.1016/j.envint.2014.05.009.

[51] M.R. Boleda, M.T. Galceran, F. Ventura, Behavior of pharmaceuticals and drugs of abuse in a drinking water treatment plant (DWTP) using combined conventional and ultrafiltration and reverse osmosis (UF/RO) treatments, Environ. Pollut. 159 (2011) 1584-1591, doi:10.1016/j.envpol.2011.02.051.

[52] P.E. Stackelberg, J. Gibs, E.T. Furlong, M.T. Meyer, S.D. Zaugg, R.L. Lippincott, Efficiency of conventional drinking-water-treatment processes in removal of pharmaceuticals and other organic compounds, Sci. Total Environ. 377 (2007) 255-272, doi:10.1016/j.scitotenv.2007.01.095.

[53] E. Mwenesongole, L. Gautam, S. Hall, T. Emmett, Estimating community drug usage patterns by the analysis of waste water, in: Proceedings of the Salford Postgraduate Annual Research Conference, University of Salford UK, 2012.

[54] K. Blau, J.M. Halket, Handbook of Derivatives for Chromatography, second ed., John Wiley and Sons, West Sussex, 1993.

[55] O.D. Sparkman, Z.E. Penton, F.G. Kitson, Gas Chromatography and Mass Spectrometry: A Practical Guide, second ed., Elsevier, Oxford, 2011.

[56] M.J. Telepchak, T.F. August, G. Chaney, Forensic and Clinical Applications of Solid Phase Extraction, Springer Science and Business Media, New York, 2004.

[57] J. Beyer, F.T. Peters, T. Kraemer, H.H. Maurer, Detection and validated quantification of toxic alkaloids in human blood plasma-comparison of LC-APCI-MS with LC-ESI-MS/MS, J. Mass Spectrom. 42 (2007) 621-633, doi:10.1002/jms.1191.

[58] L. Couchman, P.E. Morgan, LC-MS in analytical toxicology: some practical considerations, Biomed. Chromatogr. 25 (2011) 100-123, doi:10.1002/bmc.1566

[59] M. Sargent, Guide to achieving reliable quantitative LC-MS measurements, RSC Analytical Methods Committee. < http://www.rsc.org/images/ AMC\%20LCMS\%20Guide_tcm18-240030.pdf>. 2013 (accessed 23.06.15).

[60] M. Holčapek, R. Jirásko, M. Lísa, Recent developments in liquid chromatography-mass spectrometry and related techniques, J. Chromatogr. A 1259 (2012) 3-15, doi:10.1016/j.chroma.2012.08.072.

[61] M.J. Focazio, D.W. Kolpin, K.K. Barnes, E.T. Furlong, M.T. Meyer, S.D. Zaugg, et al., A national reconnaissance for pharmaceuticals and other organic wastewater contaminants in the United States - II) Untreated drinking water sources, Sci. Total Environ. 402 (2008) 201-216, doi:10.1016/j.scitotenv.2008.02.021.

[62] E. de Hoffmann, V. Stroobant, Mass Spectrometry: Principles and Applications, third ed., John Wiley and Sons, West Sussex, 2007.

[63] C. Rosal, D. Betowski, J. Romano, J. Neukom, D. Wesolowski, L. Zintek, The development and inter-laboratory verification of LC-MS libraries for organic chemicals of environmental concern, Talanta 79 (2009) 810-817, doi:10.1016/ j.talanta.2009.05.004.

[64] A.C. Hogenboom, J.A. van Leerdam, P. de Voogt, Accurate mass screening and identification of emerging contaminants in environmental samples by liquid chromatography-hybrid linear ion trap Orbitrap mass spectrometry, J. Chromatogr. A 1216 (2009) 510-519, doi:10.1016/j.chroma.2008.08 053 .

[65] S.C. Turfus, R.A. Braithwaite, D.A. Cowan, M.C. Parkin, N.W. Smith, A.T. Kicman, Metabolites of lorazepam: relevance of past findings to present day use of LC-MS/MS in analytical toxicology, Drug Test. Anal. 3 (2011) 695-704, doi:10.1002/dta.305. 
[66] United Nations Office on Drugs and Crime, World Drug Report 2015, United Nations Publication. <https://www.unodc.org/documents/wdr2015/World Drug_Report_2015.pdf>. 2015 (accessed 05.19.16).

[67] I. Senta, I. Krizman, M. Ahel, S. Terzic, Integrated procedure for multiresidue analysis of dissolved and particulate drugs in municipal wastewater by liquid chromatography-tandem mass spectrometry, Anal. Bioanal. Chem. 405 (2013) 3255-3268, doi:10.1007/s00216-013-6720-9.

68] A.L.N. Van Nuijs, B. Pecceu, L. Theunis, N. Dubois, C. Charlier, P.G. Jorens, et al., Can cocaine use be evaluated through analysis of wastewater? A nation-wide approach conducted in Belgium, Addiction 104 (2009) 734-741, doi:10.1111/ j.1360-0443.2009.02523.x.

[69] C.J. Naden, The A-Z of Drugs, Marshall Cavendish Benchmark, New York, 2008.

[70] C.L. O'Neal, A. Poklis, Simultaneous determination of acetylcodeine, monoacetylmorphine, and other opiates in urine by GC-MS, J. Anal. Toxicol. 21 (1997) 427-432, doi:10.1093/jat/21.6.427.

[71] M.W. LeChevallier, K. Au, Water Treatment and Pathogen Control: Process Efficiency in Achieving Safe Drinking-Water, IWA Publishing, London, 2004.

[72] P. Westerhoff, Y. Yoon, S. Snyder, E. Wert, Fate of endocrine-disruptor, pharmaceutical, and personal care product chemicals during simulated drinking water treatment processes, Environ. Sci. Technol. 39 (2005) 6649-6663, doi:10.1021/es0484799.

[73] A.C. Moffat, M.D. Osselton, B. Widdop, J. Watts, Clarke's Analysis of Drugs and Poisons, fourth ed., Pharmaceutical Press, London, 2011.

[74] European Monitoring Centre for Drugs and Drug Addition, Cocaine and crack drug profile. <http://www.emcdda.europa.eu/publications/drug-profiles/ cocaine>. 2015 (accessed 10.03.16)

[75] P.K. Nayak, A.L. Misra, S.J. Mulé, Physiological disposition and biotransformation of $(3 \mathrm{H})$ cocaine in acutely and chronically treated rats, J. Pharmacol. Exp. Ther. 196 (1976) 556-569, doi:10.1007/s11270-011-1010-7.

[76] H. Friedman, H.R. Ochs, D.J. Greenblatt, R.I. Shader, Tissue distribution of diazepam and its metabolite desmethyldiazepam: a human autopsy study,
J. Clin. Pharmacol. 25 (1985) 613-615, doi:10.1002/j.1552-4604.1985 tb02888.x.

[77] E.J. Cone, W.W. Weddington, Prolonged occurrence of cocaine in human saliva and urine after chronic use, J. Anal. Toxicol. 13 (1989) 65-68, doi:10.1093/jat/ 13.2.65.

[78] C.L. Duvauchelle, T. Sapoznik, C. Kornetsky, The synergistic effects of combining cocaine and heroin ("Speedball") using a progressive-ratio schedule of drug reinforcement, Pharmacol. Biochem. Behav. 61 (1998) 297-302, doi:10.1016/ S0091-3057(98)00098-7.

[79] I. González-Mariño, J.B. Quintana, I. Rodríguez, N. Sánchez-Méndez, R. Cela, Transformation of cocaine during water chlorination, Anal. Bioanal. Chem. 404 (2012) 3135-3144, doi:10.1007/s00216-012-6428-2

[80] I. González-Mariño, I. Rodríguez, J.B. Quintana, R. Cela, Investigation of the transformation of 11-nor-9-carboxy- $\Delta{ }^{9}$-tetrahydrocannabinol during water chlorination by liquid chromatography-quadrupole-time-of-flight-mass spectrometry, J. Hazard. Mater. 261 (2013) 628-636, doi:10.1016/ j.jhazmat.2013.08.006.

[81] I. González-Mariño, J.B. Quintana, I. Rodríguez, M. Cores, R. Cela, Transformation of methadone and its main human metabolite, 2-ethylidene-1, 5-dimethyl-3, 3-diphenylpyrrolidine (EDDP), during water chlorination, Water Res. 68 (2015) 759-770, doi:10.1016/j.watres.2014.10.058.

[82] M.S. Díaz-Cruz, M.J. López de Alda, R. López, D. Barceló, Determination of estrogens and progestogens by mass spectrometric techniques (GC/MS, LC/MS and LC/MS/MS), J. Mass Spectrom. 38 (2003) 917-923, doi:10.1002/jms.529.

[83] Advisory Council on the Misuse of Drugs, Annual report on the home office forensic early warning system (FEWS) - a system to identify new psychoactive substances in the UK, Home Office, London. <https://www.gov.uk/government uploads/system/uploads/attachment_data/file/225840/fews.pdf >. 2012 (accessed 10.11.15).

[84] E.M. Mwenesongole, L. Gautam, S.W. Hall, J.W. Waterhouse, M.D. Cole Simultaneous detection of controlled substances in waste water, Anal. Methods 5 (2013) 3248-3254, doi:10.1039/C3AY40655E. 